\title{
Presynaptic Ryanodine-Sensitive Calcium Stores Contribute to Evoked Neurotransmitter Release at the Basket Cell-Purkinje Cell Synapse
}

\author{
Micaela Galante and Alain Marty \\ Laboratoire de Physiologie Cérébrale, Université Paris 5, 75006 Paris, France
}

\begin{abstract}
Presynaptic terminals of cerebellar basket cells are known to contain ryanodine-sensitive calcium stores (RyCSs); recently, it has been shown that these stores control the frequency of miniature synaptic currents in the absence of presynaptic spiking. Here, using paired recordings of basket cell-Purkinje cell synapses, we show that blocking the RyCSs with high concentration of ryanodine decreases the mean amplitude of evoked IPSCs to $70 \%$ of the control value. The paired-pulse ratio and failure rate increase, indicating that the reduction stems from a decreased probability of evoked neurotransmitter release. Various control experiments eliminate the possibility of an indirect effect of ryanodine via activation of postsynaptic receptors. Prolonged application of cyclopiazonic acid, a blocker of the endoplasmic reticulum calcium pump, totally abolishes the ryanodine action. Our results indicate that calcium released from presynaptic RyCSs enhances the amplitude of evoked GABAergic synaptic currents. The precise mechanism by which calcium released from internal stores affect action potential-dependent release is unknown; however, our results suggest that these stores do not provide additional calcium for each presynaptic action potential; rather, they appear to enhance depolarization-induced calcium signals indirectly, perhaps by increasing the basal level of cytosolic calcium concentration in the vicinity of release sites.
\end{abstract}

Key words: basket cell; Purkinje cell; paired recordings; ryanodine; ryanodine-sensitive calcium stores; cerebellum; perforated-patch

\section{Introduction}

It is well known that calcium drives neurotransmitter release, and it is generally accepted that the source of calcium that triggers action potential-evoked release in synaptic terminals is the extracellular fluid. New results raise, however, the possibility that presynaptic calcium stores could participate in triggering neurotransmitter release. The frequency and/or amplitude of miniature IPSCs (mIPSCs) recorded in hippocampal pyramidal cells (Savic and Sciancalepore, 1998) or cerebellar Purkinje cells (Llano et al., 2000; Bardo et al., 2002), as well as those of miniature EPSCs (mEPSCs) recorded in cultured hippocampal pyramidal cells (Emptage et al., 2001) and in cortical pyramidal cells (Simkus and Stricker, 2002), are sensitive to ryanodine and to other agents controlling ryanodine-sensitive calcium stores (RyCSs). These effects have been attributed to the modulation of randomly occurring calcium transients in presynaptic terminals (Llano et al., 2000; Emptage et al., 2001), similar to the storedriven "calcium sparks" occurring in resting muscle fibers (Cheng et al., 1993).

These observations show that presynaptic calcium stores, in-

Received July 29, 2003; revised 0ct. 16, 2003; accepted 0ct. 18, 2003.

This work was supported by Centre National de la Recherche Scientifique (Unité Mixte de Recherche 8118) and Région lle de France (Sésame Programme). M.G. was supported by a Marie Curie Fellowship of the European Community Programme Quality of Life under contract number QLGA-CT-2000-51136 and by the Fondation pour la Recherche Médicale. We thank Prof. Philippe Ascher, Prof. Thibault Collin, and Dr. Marco Diana for helpful comments on this manuscript and Dr. Christophe Pouzat and Dr. Marco Diana for sharing their analysis software.

Correspondence should be addressed to Dr. Micaela Galante, Laboratoire de Physiologie Cérébrale, Université Paris 5, 45 rue des Saints Pères, 75270 Paris Cedex 06, France. E-mail: micaela.galante@univ-paris5.fr. Copyright $\odot 2003$ Society for Neuroscience $\quad$ 0270-6474/03/2311229-06\$15.00/0 cluding RyCSs, play a role in controlling transmitter release under resting conditions. The situation concerning action potential-evoked synaptic transmission is much less clear. At the frog neuromuscular junction, RyCSs can modulate presynaptic calcium transients and neurotransmitter release after repetitive stimulation in a low-Ca/high-Mg medium (Narita et al., 1998). In bullfrog sympathetic ganglia, block of ryanodine receptors (RyRs) inhibits presynaptic calcium transients evoked by trains of action potentials but not the responses to single action potentials (Peng, 1996). In the guinea pig vas deferens, junction potentials elicited by trains of presynaptic action potentials in the presence of a blocker of N-type calcium channel are strongly inhibited by ryanodine (Smith and Cunnane, 1996). In the lamprey, release of calcium from internal stores can enhance transmitter release from reticulospinal neurons in response to activation of presynaptic group I metabotropic glutamate receptors (Cochilla and Alford, 1998). However, in all of these studies, participation of presynaptic calcium stores in evoked transmitter release occurred only after their activation by high-frequency stimulation or by group I metabotropic glutamate receptor agonists. Furthermore, there are no comparable data for mammalian central synapses. In a recent study, calcium released from intracellular calcium stores was found to exert little or no influence on a series of excitatory central synapses (Carter et al., 2002), but another study (Emptage et al., 2001) showed that, at one of those synapses, calcium released from internal stores contributes to presynaptic calcium transients and to mEPSC frequency.

In this work, we used paired recordings between basket cells 
and synaptically connected Purkinje cells of the cerebellum to evaluate the contribution of internal calcium stores to GABA release. At this synapse, there is immunohistochemical evidence for the presence of ryanodine receptors in presynaptic terminals, and the existence of calcium sparks and of presynaptic effects of ryanodine on mIPSCs have been firmly established (Llano et al., 2000; Bardo et al., 2002). We found that block of ryanodine receptors inhibits release, showing that presynaptic ryanodinesensitive calcium stores exert a regulatory role on evoked neurotransmitter release.

\section{Materials and Methods}

Slice preparation and materials. All experiments were performed on parasagittal cerebellar slices from Sprague Dawley juvenile rats (11 to $13 \mathrm{~d}$ of age). Briefly, after decapitation, the cerebellar vermis was isolated and placed in an oxygenated bicarbonate-buffered saline (BBS) at $3^{\circ} \mathrm{C}$, and 180 - $\mu \mathrm{m}$-thick slices were cut using a VT1000S Vibratome (Leica, Nussloch, Germany). Slices were stored for $1 \mathrm{hr}$ at $34^{\circ} \mathrm{C}$ and then kept at room temperature. For electrophysiological recording, the slice was superfused $(1-1.5 \mathrm{ml} / \mathrm{min})$ with BBS at room temperature in the recording chamber. Neurons were visually identified using an upright microscope (Axioskop; Zeiss, Oberkochen, Germany) equipped with differential interference contrast optics and with a water immersion $63 \times, 0.9$ numerical aperture objective. The microscope was connected to a fluorescence lamp (Welch Allyn, Skaneateles Falls, NY) by an optic fiber bundle; it was then possible to use it as an epifluorescence microscope when required. The BBS contained the following (in mM): $125 \mathrm{NaCl}, 2.5 \mathrm{KCl}, 2 \mathrm{CaCl}_{2}, 1$ $\mathrm{MgCl}_{2}, 1.25 \mathrm{NaH}_{2} \mathrm{PO}_{4}, 26 \mathrm{NaHCO}_{3}$, and 10 glucose. The $\mathrm{pH}$ was 7.4 after the solution was bubbled with $95 \% \mathrm{O}_{2}$ and $5 \% \mathrm{CO}_{2}$.

Electrophysiology. Pipettes were pulled from borosilicate glass capillaries and had a resistance of 3-3.5 $\mathrm{M} \Omega$ for the Purkinje cells and 12-13 $\mathrm{M} \Omega$ for interneurons when filled with intracellular solutions.

Purkinje cells were voltage clamped using the whole-cell configuration, and the membrane potential was held at $-60 \mathrm{mV}$. Series resistance was compensated $(70-75 \%)$ and checked throughout the experiment; the experiment was discontinued if the uncompensated series resistance increased above $10 \mathrm{M} \Omega$. For Purkinje cells, most of the experiments were performed with an internal solution of the following composition (in mM): 109 Cs-gluconate, $20 \mathrm{CsCl}, 4.6 \mathrm{MgCl}_{2}, 1 \mathrm{CaCl}_{2}, 10$ HEPES, 10 BAPTA-tetracesium salt, $4 \mathrm{Na}$-ATP, and $0.4 \mathrm{Na}-\mathrm{GTP}$. In other experiments, the internal solution contained the following (in mM): 124 Csgluconate, $20 \mathrm{CsCl}, 4.6 \mathrm{MgCl}_{2}, 0.1 \mathrm{CaCl}_{2}, 10 \mathrm{HEPES}, 1 \mathrm{EGTA}, 4 \mathrm{Na}$-ATP, and $0.4 \mathrm{Na}-\mathrm{GTP}$. The $\mathrm{pH}$ was adjusted to 7.3 with $\mathrm{CsOH}$, and the osmolarity was 295-300 mOsm. For some experiments, we used the same composition of $10 \mathrm{~mm}$ BAPTA internal solution, except that we had 40 mM BAPTA and we added Cs-gluconate as much as necessary to reach the osmolarity value of 295-300 mOsm.

Basket cells were recorded using the perforated-patch technique (Diana et al., 2002): amphotericin B was dissolved in DMSO $(2 \mathrm{mg} / 30 \mu \mathrm{l})$ and added (1:250 dilution) in an intracellular solution containing the following (in mM): $135 \mathrm{~K}$-gluconate, $4.6 \mathrm{MgCl}_{2}, 0.1 \mathrm{CaCl}_{2}, 10 \mathrm{HEPES}, 1$ EGTA, 4 Na-ATP, and $0.4 \mathrm{Na}-\mathrm{GTP}$, pH 7.3 with $\mathrm{KOH}$. In many experiments, Lucifer yellow $(0.1 \mathrm{mg} / \mathrm{ml})$ was added to this intracellular solution to monitor the perforated-patch configuration: the fluorescent dye was visible only in the patch pipette during perforated-patch recording, whereas a labeling of the neuron was a clear sign of spontaneous transition to whole-cell recording. In the latter case, the experiment was immediately stopped. Presynaptic neurons were voltage clamped at -60 to $-70 \mathrm{mV}$, and unclamped action currents were generated by short (4-10 msec) depolarizing pulses typically to 0 or $+20 \mathrm{mV}$ from the holding potential. For the paired-pulse experiments, the onsets of the two pulses were separated by $30 \mathrm{msec}$. This double stimulation was repeated every 3 sec throughout the entire duration of the experiment.

During electrophysiological recordings, the BBS always contained 10 $\mu \mathrm{M}$ 2,3-Dioxo-6-nitro-1,2,3,4-tetrahydrobenzo[f]quinoxaline-7-sulphonamide disodium (Tocris Cookson, Ballwin, MO) and $50 \mu \mathrm{M} \mathrm{D}-\mathrm{AP}-5$ (Tocris Cookson) to block AMPA/kainate and NMDA receptors, respectively. Ryanodine mixture (Calbiochem, La Jolla, CA) was dissolved in water, whereas stocks of AM-251 (Tocris Cookson) and cyclopiazonic acid (CPA) (Sigma, St. Louis, MO) were prepared in DMSO. AM-251 was diluted 5000 times, whereas CPA was diluted 2000 times (final concentration of 0.5 and $25 \mu \mathrm{M}$, respectively).

Data acquisition and analysis. Paired recordings were obtained with two patch-clamp amplifiers: an EPC-9 (HEKA Elektronik, Darmstadt, Germany) and an Axopatch 200A (Axon Instruments, Foster City, CA). Data were sampled at $5 \mathrm{kHz}$ and filtered at $2 \mathrm{kHz}$. They were analyzed using Igor (Wavemetrics, Lake Oswego, OR) and in-house developed routines. Mean control amplitudes of evoked IPSCs (eIPSCs) were calculated averaging at least 100 amplitude values (failures included) measured just before drug application, and a similar number of eIPSCs were averaged around the time of maximal effect of the drug. The paired-pulse ratio (PPR) was calculated for groups of 20 consecutive sweeps as the ratio of the mean amplitude of the second eIPSC to the mean of the first eIPSC (Kim and Alger, 2001). Control and ryanodine PPRs were obtained for individual experiments by averaging these single control and ryanodine PPR values. Data from different experiments were averaged to obtain the PPR mean control value, and, finally, both control and ryanodine PPR data for each experiment were normalized to this control PPR value. Similarly, the coefficient of variation (CV) of the eIPSC amplitude was calculated as the ratio between the SD and the mean amplitude evaluated for groups of 20 consecutive sweeps. The Wilcoxon signed rank test and the Mann-Whitney test were used to identify statistical significance among groups. Data were considered significantly different when $p<0.05$. Averages are given with SE.

\section{Results}

\section{Effects of ryanodine on eIPSCs}

Simultaneous recordings from a presynaptic basket neuron and a functionally connected Purkinje neuron were obtained. We used the perforated-patch technique for the presynaptic cell because it has been shown recently (Diana and Marty, 2003) that this prevents the rundown of the eIPSCs observed in conventional whole-cell paired recordings (Vincent and Marty, 1996). Moreover, this method preserved the calcium buffer system of the basket cell, an important consideration when studying the role of presynaptic stores in neurotransmitter release.

Depolarizing steps delivered to basket cell soma generated action currents that propagated along the axon (Tan and Llano, 1999) and gave rise to eIPSCs in the synaptically connected Purkinje cell (Fig. 1 $A a$ ). To study the contribution of calcium released from intracellular stores to the neurotransmission, we added $100 \mu \mathrm{M}$ ryanodine to the extracellular solution. This drug concentration is known to irreversibly block RyRs in presynaptic terminals (Mothet et al., 1998; Llano et al., 2000). After a variable delay (5-6 min), the eIPSC amplitude decreased (Fig. 1 $A b, B$ ). The effect was observed in all experiments $(n=13)$, although the extent of the inhibition varied somewhat among experiments (Fig. 1C). On average, the mean eIPSC amplitude was reduced to $67.9 \pm 4.6 \%$ of the control $(n=13)$, whereas eIPSC kinetics were not significantly affected (data not shown). The reduction induced by RyR block was not correlated with the eIPSC amplitude in control (linear fit, $p=0.2$ ). This reduction was not reversible during washing of ryanodine.

It has been reported that micromolar ryanodine concentrations lock the channel in an open subconductance state leading to calcium release from internal stores (Bezprozvanny et al., 1991). Therefore, the effect of 5-10 $\mu \mathrm{M}$ ryanodine on eIPSCs was also studied. The main effect observed in all pairs tested was characterized by eIPSC amplitude depression developing $\sim 10 \mathrm{~min}$ of drug application (to $77.5 \pm 2.1 \%$ of the control; $n=9 ; p<0.05$; data not shown). In a subpopulation of basket cell-Purkinje cell pairs (four of nine), the effect of the drug was biphasic, consisting of a transient enhancement of the eIPSC amplitude followed by 
A
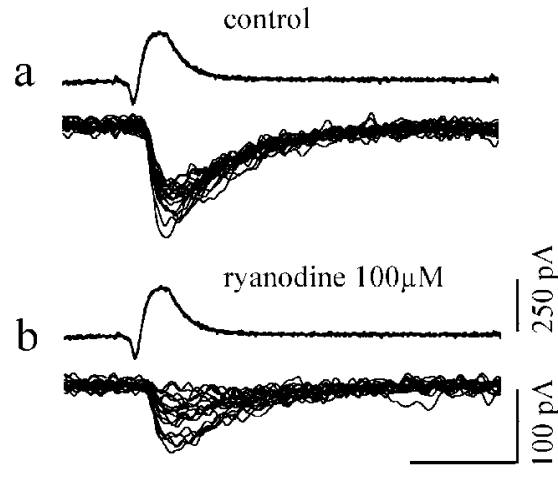

$\mathrm{B}$

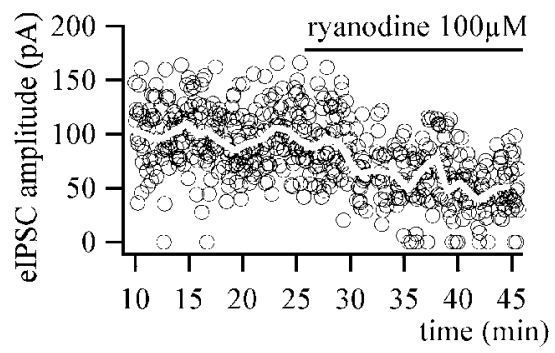

$\mathrm{C}$

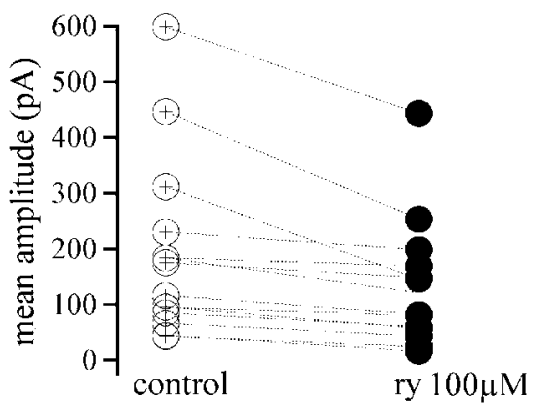

Figure 1. RyCSs are involved in GABA release at the basket cell-Purkinje cell synapse. A, Action currents generated in a basket cell by depolarizing steps evoke IPSCs in a connected Purkinje cell. Presynaptic and postsynaptic current sweeps are superimposed before $(a)$ and after ( $b$ ) bath addition of ryanodine. Leak subtraction was applied to the presynaptic trace. $B$, Same experiment as in $A$; peak amplitudes of eIPSCs plotted in function of the time. Time 0 corresponds to initiation of Purkinje whole-cell recording. The superimposed line represents the mean elPSC amplitude time course (every 20 sweeps). C, Mean elPSC amplitudes are shown for $n=13$ pairs in control (open circles) and after application of ryanodine (filled circles; ry).

the usual late inhibition (data not shown). Such effects are consistent with the excitatory effects of 5-10 $\mu \mathrm{M}$ ryanodine on mIPSC frequency (Llano et al., 2000; Bardo et al., 2002) and on presynaptic calcium sparks (Llano et al., 2000). In the following experiments, the higher ryanodine concentration $(100 \mu \mathrm{M})$ was used systematically to obtain a stable depressing effect.

\section{Block of RyRs decreases the release probability}

Three different methods were used to evaluate a possible change in release probability.

In most experiments, a presynaptic paired-pulse protocol was applied. Two short pulses separated by $30 \mathrm{msec}$ were used, and the ratio between the amplitude of the second eIPSC and the amplitude of the first eIPSC (PPR) was measured. As exemplified in Fig. $2 A$, the amplitude of the second eIPSC decreased in the presence of ryanodine (to $74 \pm 5 \%$ of the control; $n=12$ ), but the PPR increased significantly (from $100 \pm 5$ to $111 \pm 4 \% ; n=12$; $p<0.05$ ) (Fig. 2B). The CV of eIPSCs and the percentage of failures are two additional parameters that are related to presyn-
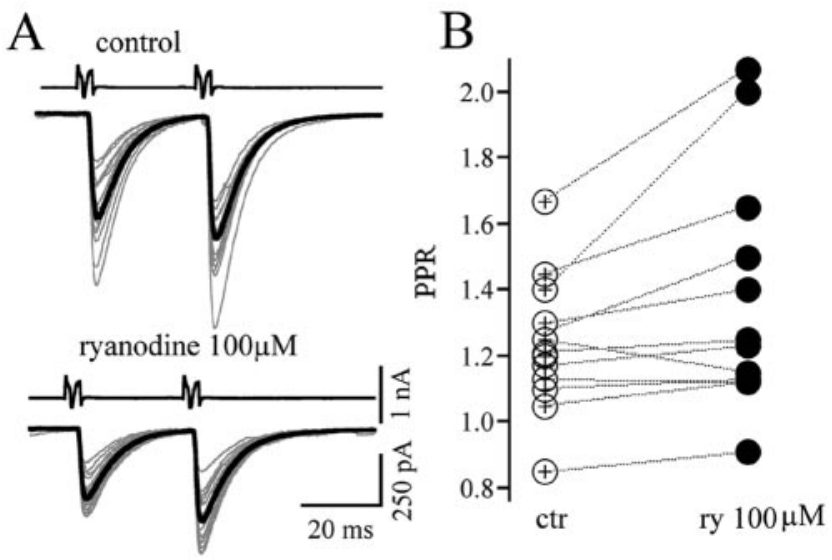

C

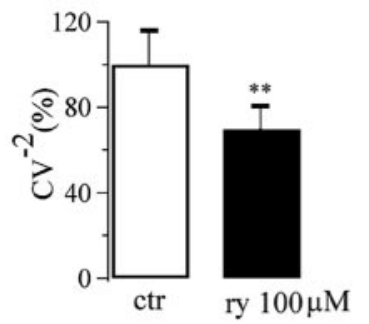

$\mathrm{D}$

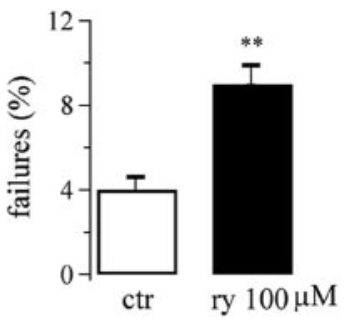

Figure 2. Block of RyRs decreases the probability of release. A, Superimposed elPSCs (gray lines) recorded in a Purkinje cell after induction of two action currents (30 msec interpulse interval) in a presynaptic basket cell. elPS(s are shown in control (top) and during ryanodine application (bottom); thick black traces represent the average eIPSCS. B, Paired-pulse ratio calculated in $n=12$ pairs in control (ctr) and during RyR (ry) block. C, The $\mathrm{CV}^{-2}$ decreases during block of ryanodine receptors. $\mathrm{CV}^{-2}$ values are normalized relative to control values $(n=$ 12). $D$, Average failure percentage in the absence and in the presence of ryanodine $(n=8)$.

aptic function. The square inverse of the $\mathrm{CV}\left(\mathrm{CV}^{-2}\right)$ has been shown to increase with manipulations increasing the release probability and to decrease when release probability is decreased (Clements, 1990; Malinow and Tsien, 1990). We found that $\mathrm{CV}^{-2}$ decreased from $6.35 \pm 1.01$ in control to $4.42 \pm 0.68$ in ryanodine $(p<0.05 ; n=12$ ) (Fig. $2 C$ ), whereas the failure frequency was $4 \pm 0.6$ and $9.3 \pm 0.9 \%(p<0.05 ; n=8)$ in control and in ryanodine, respectively (Fig. $2 D$ ). On the basis of the analyses of PPR, of $\mathrm{CV}^{-2}$, and of the failure rate, we conclude that at least a large part of the effects of ryanodine are presynaptic and that they involve a reduction in the probability of transmitter release.

Changes in the quantal size can be estimated by calculating the variance to mean ratio of eIPSC amplitudes. The variance/mean (as calculated for the first eIPSCs) was $33.8 \pm 6.7 \mathrm{pA}$ in control and $30.7 \pm 8.1 \mathrm{pA}$ during RyR block $(n=13)$, indicating no significant change in the quantal size.

Retrograde signaling from Purkinje neurons does not account for ryanodine effects

The previous results suggest that, at the basket cell-Purkinje cell synapse, calcium released from presynaptic stores through RyRs contributes to GABA release, but they do not rule out an additional postsynaptic contribution. The possibility of a nonspecific effect of ryanodine on $\mathrm{GABA}_{\mathrm{A}}$ receptors was excluded by previous experiments showing that ryanodine does not affect the Purkinje cell response to the $\mathrm{GABA}_{\mathrm{A}}$ receptor agonist muscimol (Llano et al., 2000). A second possibility would be that ryanodine acts on postsynaptic calcium stores to increase the calcium con- 


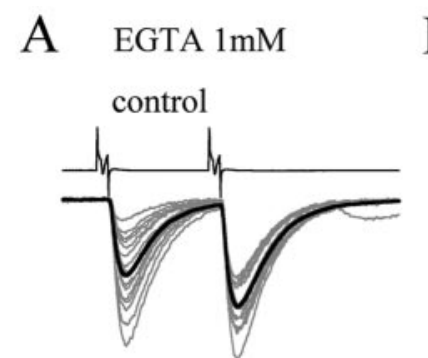

B $\quad$ AM-251
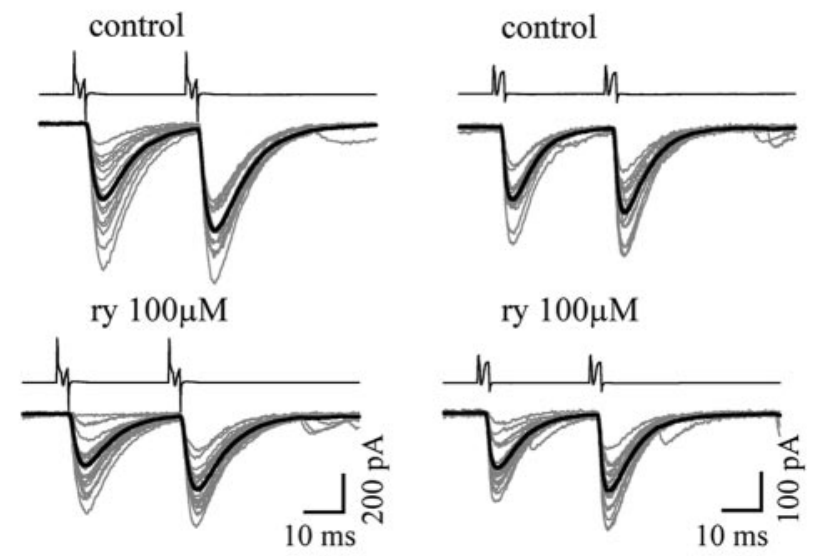

$\mathrm{C}$

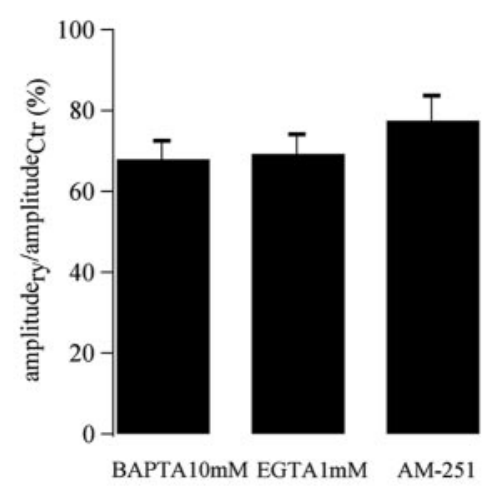

Figure 3. Retrograde messenger release by Purkinje neurons does not significantly contribute to the ryanodine effect. $A$, elPSC amplitudes elicited in a Purkinje neuron loaded with $1 \mathrm{~mm}$ EGTA in control (top) and in ryanodine (bottom; ry). Averaged currents are superimposed (black trace). $B$, Block of RyRs still reduces elPSCs when B $_{1}$ receptors are blocked with $0.5 \mu \mathrm{m}$ AM-251. C, Reduction of elPSCs by ryanodine is similar when buffering the Purkinje cell with $10 \mathrm{~mm}$ BAPTA (first column; $n=13$ ) or with $1 \mathrm{~mm}$ EGTA (second column; $n=7$ ) and in the presence of AM-251 (third column; $n=8$ ). Values are normalized with respect to the control (Ctr) elPSC amplitude. There are no significant differences between the three mean values.

centration in the postsynaptic Purkinje cells and to induce depolarization-induced suppression of inhibition (DSI) (Llano et al., 1991; Vincent et al., 1992). This retrograde signaling is highly sensitive to intracellular calcium increases in Purkinje cells (Glitsch at al., 2000), and it relies on a Ca-dependent production of cannabinoids in Purkinje cells (Kreitzer and Regehr, 2001; Diana et al., 2002). Ryanodine is a mixed activator-inhibitor of RyRs, and the net effect becomes more inhibitory as the concentration is increased. We used a very large concentration of ryanodine $(100 \mu \mathrm{M})$, which was unlikely to induce any substantial calcium elevation in the postsynaptic cell, and therefore the possibility of a retrograde inhibition seemed rather remote. Nevertheless, we tried to evaluate whether a component of the ryanodine effect could come from retrograde inhibition. First, we changed the calcium buffer of the Purkinje cell recording solution from $10 \mathrm{~mm}$ BAPTA to $1 \mathrm{~mm}$ EGTA (Fig. $3 A$ ). In $n=7$ pairs tested, ryanodine reduced the eIPSC amplitude to $69.2 \pm 4.9 \%$ of the control (Fig. 3C). The square inverse of the coefficient of variation decreased from $12.6 \pm 2.7$ to $9.8 \pm 1.9(n=7 ; p<$ $0.05)$, and the PPR increased to $110.2 \pm 3.3 \%(n=5)$. These values are almost identical to those found with $10 \mathrm{~mm}$ BAPTA.
We also increased the calcium buffering, using $40 \mathrm{~mm}$ BAPTA in the intracellular solution for the Purkinje cell, and we found that mean eIPSC amplitude was reduced by ryanodine to $66 \pm 4 \%$ of the control $(n=3)$. Thus, altering calcium buffering in the postsynaptic cell does not change the effects of ryanodine.

In a second series of experiments, we tested the possibility that ryanodine acting on neighboring Purkinje cell would trigger endocannabinoid release and hence inhibit neurotransmitter release from presynaptic terminals. It has been shown recently that endogenous cannabinoids act in this system as retrograde messengers by activating presynaptic $\mathrm{CB}_{1}$ receptors (Kreitzer and Regehr, 2001; Diana et al., 2002). Therefore, paired recordings were performed in the presence of the $\mathrm{CB}_{1}$ receptor antagonist AM-251. Under these conditions, the retrograde inhibition of eIPSCs is completely blocked (Diana et al., 2002), yet ryanodine still reduced the eIPSC amplitude to $77.5 \pm 5.4 \%$ of the control; the ratio was not significantly different from that obtained without AM-251 $(n=8, p>0.05)$ (Fig. $3 B, C)$. We conclude that ryanodine does not produce its effects via retrograde inhibition.

\section{Block of endoplasmic reticulum calcium pump disrupts ryanodine effects}

The refilling of calcium stores is controlled by SERCA (sarcoplasmic/endoplasmic reticulum calcium ATPase) pumps, a family of $\mathrm{Ca} / \mathrm{ATP}$ ases whose activity is selectively blocked by CPA. CPA has been shown to increase the frequency of mIPSCs in interneurons (Bardo et al., 2002) (similar results were independently obtained in our laboratory; J. Gonzalez, A. Marty, and I. Llano, unpublished results). This suggests that blocking the pump leads to a sustained increase in cytosolic calcium concentration in presynaptic terminals, presumably attributable to uncompensated leakage from the calcium stores. To test whether CPA had shortterm effects on evoked GABA release, six pairs were exposed to 25 $\mu \mathrm{M}$ CPA. After $20 \mathrm{~min}$ of CPA superfusion, neither the mean eIPSC amplitude (which changed to $89 \pm 8 \%$ of the control; $n=$ 6; $p>0.05$; data not shown) nor the PPR (1.07 \pm 0.04 in the control and $1.09 \pm 0.05$ in CPA) were significantly affected; however, block of RyRs with $100 \mu \mathrm{M}$ ryanodine was still effective in reducing the eIPSC amplitude to $75 \pm 7 \%$ of the control $(n=5$; $p<0.05$ ) (Fig. $4 B$ ). These results indicate that either ryanodine does not act on CPA-sensitive stores or the collapse of the storecytosol gradient is a slow process that was not completed in these experiments because of the comparatively short duration of drug incubation. To distinguish between the two possibilities, slices were incubated in $25 \mu \mathrm{M}$ CPA for $2-6 \mathrm{hr}$ instead of maintaining them in normal saline and were then used for electrophysiology. As shown in Figure $4 A$, this procedure abolished the effects of ryanodine on eIPSC amplitudes. On average, eIPSC amplitudes were $95.6 \pm 2.8 \%$ of the control $(n=4$ pairs from four different incubated preparations) (Fig. $4 B$ ). Together, these results indicate that ryanodine acts on CPA-sensitive calcium stores, that it can only inhibit eIPSCs if these calcium stores are normally loaded with calcium, and that CPA addition leads to a slow emptying of the stores, which needs $>20$ min for completion.

\section{Discussion}

The present results indicate that, at the basket cell-Purkinje cell synapse, mobilization of $\mathrm{Ca}^{2+}$ from presynaptic calcium stores contributes to GABA release. Blocking ryanodine receptors results in a 30\% reduction in eIPSC amplitude. Because the pairedpulse ratio was increased and the failure rate was decreased, whereas the quantal size was not significantly modified, we con- 
A
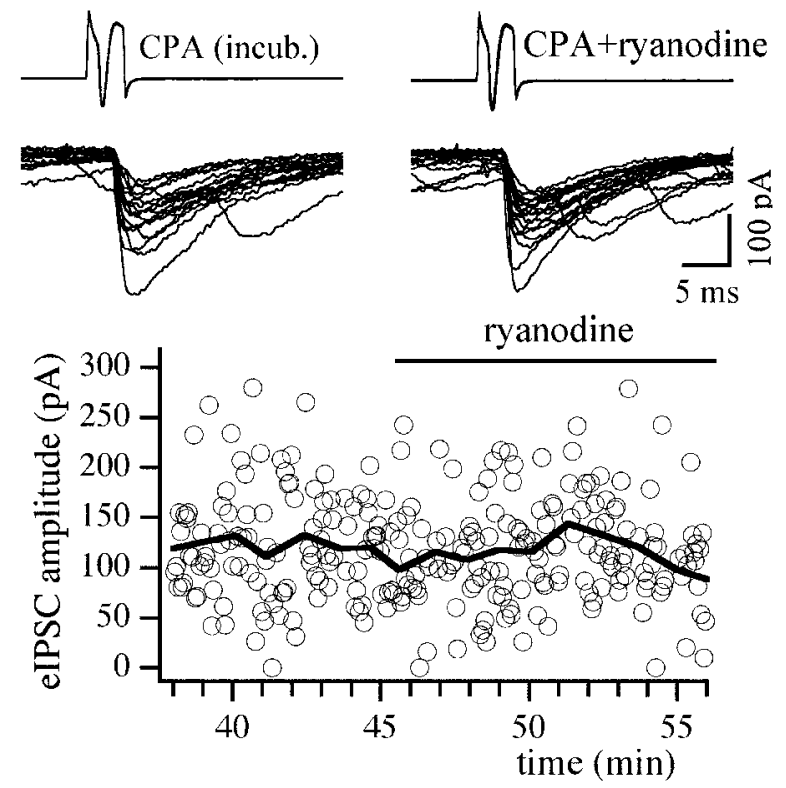

B

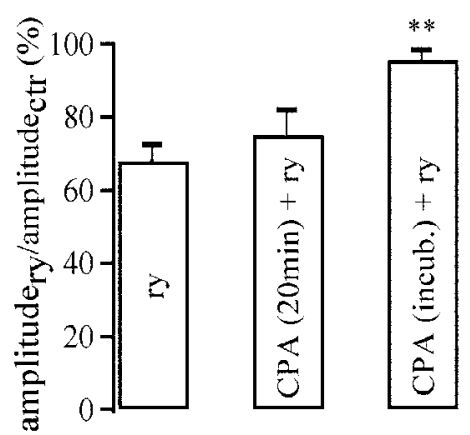

Figure 4. Emptying calcium stores with long-lasting CPA incubation abolishes the effects of ryanodine. A, After 2 hr incubation in the SERCA pump inhibitor ( $25 \mu \mathrm{M} C P A$; also applied during the recording) block of RyRs fails to affect eIPSC amplitude. The line represents the eIPSC mean amplitude calculated every 20 trials. Top traces represent presynaptic action currents and eIPSCs before and after ryanodine addition (same pair as in the plot). B, Summary graph of the magnitude of ryanodine (ry) effect on eIPSC amplitude in normal saline (first column; $n=13$ ), after exposure of CPA for 20-30 $\mathrm{min}$ (second column; $n=5$ ), and after $>2 \mathrm{hr}$ incubation with CPA (third column; $n=4)$. ctr, Control.

clude that ryanodine receptor blockade acts at a presynaptic locus.

One potential pitfall of using ryanodine in this synapse is the possible intervention of DSI after a ryanodine-induced postsynaptic calcium rise. Our standard experimental conditions were designed to minimize such a possibility in two ways: by using a large concentration of ryanodine, which was likely to have a purely inhibitory effect on RyCSs, and by strongly buffering the Purkinje cell $\mathrm{Ca}_{\mathrm{i}}$. In addition, the ryanodine effects could not be modified by removing the postsynaptic calcium buffer or by blocking presynaptic $\mathrm{CB}_{1}$ receptors, suggesting that they are not attributable to endocannabinoid-driven retrograde signaling from Purkinje neurons.

\section{Possible mechanisms of action of RyCSs in basket cell terminals}

Presynaptic RyCSs can influence eIPSCs in more than one way. In the simplest hypothesis, RyCSs act as a relay between voltage- dependent calcium channels (VDCCs) and vesicular release: for each incoming presynaptic action potential, RyCSs amplify the presynaptic calcium signal. Previous work indicates that spontaneous calcium transients (calcium sparks) occur in interneuron presynaptic terminals, that their frequency is sensitive to ryanodine, and that each calcium spark elicits the release of several GABA-containing vesicles (Llano et al., 2000). From these results, it is expected that the supplementary calcium signal provided by calcium stores would fluctuate according to the number of calcium sparks liberated by each action potential. Fluctuations in the number of sparks should then introduce multiquantal variations of the eIPSCs. This is in line with the finding of large, probably multiquantal fluctuations of eIPSC amplitudes in control conditions (Vincent and Marty, 1996; Diana and Marty, 2003). However, this scheme would predict that the size of the eIPSC amplitude fluctuations should be reduced in ryanodine; however, the variance/mean ratio, which is directly linked to these fluctuations, is unchanged in ryanodine. Therefore, our results do not indicate that ryanodine induces substantial uncoupling of vesicle synchronization during evoked neurotransmitter release. This makes the relay hypothesis unlikely.

A second possibility is that RyCSs liberate calcium after VDCC activation and that the resulting calcium rise comes too late to influence the corresponding eIPSC but sensitizes the release apparatus to a subsequent calcium entry (delayed amplification). In such a case, once RyRs are blocked, the first eIPSC of a pair should be unchanged, but the second should be reduced. Such a situation has been found in the hippocampus (Emptage et al., 2001) (but see Carter et al., 2002) and in the lamprey spinal cord [after treatment with group I metabotropic glutamate receptor agonist (Cochilla and Alford, 1998)]. In our preparation, however, we find that the first eIPSC is reduced and that the second eIPSC is actually less reduced than the first. This excludes the possibility of a delayed amplification of incoming calcium by RyCSs.

One possible way by which RyCSs could modulate transmitter release assumes that exocytosis is directly triggered by calcium coming through VDCCs, whereas RyCSs alter the sensitivity of exocytosis to incoming calcium by increasing locally the resting calcium concentration. This could be attributable to steady leak of calcium out of RyCSs. This mechanism is very similar to residual calcium-induced facilitation (Felmy et al., 2003), and it predicts that addition of ryanodine should decrease the basal cytosolic calcium concentration. Such a change would be compatible with the effect exerted by ryanodine on mIPSC frequency (Llano et al., 2000; Bardo et al., 2002). However, this change could be very modest, highly localized, and difficult to detect in very small presynaptic structures with nonratiometric calcium dyes. Another possibility assumes that VDCCs elicit calcium release from stores that are insensitive to ryanodine and to CPA, that these stores participate in phasic neurotransmitter release, and that the RyCSs modulate the sensitivity of these stores to the incoming calcium. This latter possibility is more complicated but would readily account for the evidence indicating multiquantal fluctuations at this synapse. In conclusion, the last two mechanisms proposed are compatible with our results and with previous studies; future work will be needed to distinguish between them.

\section{What physiological roles for RyCSs at inhibitory central synapses?}

The present results indicate that, at least in the GABAergic synapse investigated here, ryanodine-sensitive calcium stores are able to control the gain of the synaptic transmission. Furthermore, they show that this control is exerted under resting condi- 
tions, i. e., at low stimulation rates, and without previous exposure to neuromodulators. It seems nevertheless plausible that RyCSs can be the target of upregulation or downregulation through previous activity or after activation of presynaptic receptors. Here all experiments were performed in the presence of ionotropic glutamate receptor blockers to minimize the contribution to resting calcium trough these receptors. Molecular layer interneurons are known to have axonal NMDA (Glitsch and Marty, 1999) and AMPA receptors (Bureau and Mulle, 1998), whose activation is likely to alter the presynaptic calcium level and could modify the level of calcium loading of RyCSs. Because RyR and its associated proteins are sensitive to phosphorylation by cAMP-dependent protein kinase (Valdivia et al., 1995), another possible pathway is offered by cAMP-modifying neuromodulators. Presynaptic $\beta$-adrenergic (Kondo and Marty, 1997, 1998) and $\mathrm{CB}_{1}$ receptors (Kreitzer and Regehr, 2001; Diana et al., 2002), whose activation is likely to modify the intracellular level of cAMP, could affect the properties of the presynaptic ryanodine receptors and exert some of their effects by this pathway. It is also possible that RyCSs could control the synapse gain on a longer time scale. In the developing hippocampus, it has been shown that certain stimulation protocols lead to long-term depression of GABAergic currents, and presynaptic RyCSs are involved in this process (Caillard et al., 2000).

\section{References}

Bardo S, Robertson B, Stephens GJ (2002) Presynaptic internal $\mathrm{Ca}^{2+}$ stores contribute to inhibitory neurotransmitter release onto mouse cerebellar Purkinje cells. Br J Pharmacol 137:529-537.

Bezprozvanny I, Watras J, Ehrlich BE (1991) Bell-shaped calcium-response curves of $\operatorname{Ins}(1,4,5) \mathrm{P}_{3}$-and calcium-gated channels from endoplasmic reticulum of cerebellum. Nature 351:751-754.

Bureau I, Mulle C (1998) Potentiation of GABAergic synaptic transmission by AMPA receptors in mouse cerebellar stellate cells: changes during development. J Physiol (Lond) 509:817-831.

Caillard O, Ben-Ari Y, Gaiarsa JL (2000) Activation of presynaptic and postsynaptic ryanodine-sensitive calcium stores is required for the induction of long-term depression at GABAergic synapses in the neonatal rat hippocampus. J Neurosci 20:RC94(1-5).

Carter AG, Vogt KE, Foster KA, Regehr WG (2002) Assessing the role of calcium-induced calcium release in short-term presynaptic plasticity at excitatory central synapses. J Neurosci 22:21-28.

Cheng H, Lederer WJ, Cannell MB (1993) Calcium sparks: elementary events underlying excitation-contraction coupling in heart muscle. Science 262:740-744.

Clements JD (1990) A statistical test for demonstrating a presynaptic site of action for a modulator of synaptic amplitude. J Neurosci Methods 31:75-88.

Cochilla AJ, Alford S (1998) Metabotropic glutamate receptor-mediated control of neurotransmitter release. Neuron 20:1007-1016.

Diana MA, Marty A (2003) Characterization of depolarization-induced suppression of inhibition using paired interneuron-Purkinje cell recordings. J Neurosci 23:5906-5918.

Diana MA, Levenes C, Mackee K, Marty A (2002) Short-term retrograde inhibition of GABAergic synaptic currents in rat Purkinje cells is mediated by endogenous cannabinoids. J Neurosci 22:200-208.

Emptage NJ, Reid CA, Fine A (2001) Calcium stores in hippocampal synap- tic boutons mediate short-term plasticity, store-operated $\mathrm{Ca}^{2+}$ entry, and spontaneous transmitter release. Neuron 29:197-208.

Felmy F, Neher E, Schneggenburger R (2003) Probing the intracellular calcium sensitivity of transmitter release during synaptic facilitation. Neuron 37:801-811.

Glitsch M, Marty A (1999) Presynaptic effects of NMDA in cerebellar Purkinje cells and interneurons. J Neurosci 19:511-519.

Glitsch M, Parra P, Llano I (2000) The retrograde inhibition of IPSCs in rat cerebellar Purkinje cells is highly sensitive to intracellular $\mathrm{Ca}^{2+}$. Eur J Neurosci 12:987-993.

Kim J, Alger BE (2001) Random response fluctuations lead to spurious paired-pulse facilitation. J Neurosci 21:9608-9618.

Kondo S, Marty A (1997) Protein kinase A mediated enhancement of miniature IPSC frequency by noradrenaline in rat cerebellar stellate cells J Physiol (Lond) 498:165-176.

Kondo S, Marty A (1998) Differential effects of noradrenaline on evoked, spontaneous and miniature IPSCs in rat cerebellar stellate cells. J Physiol (Lond) 509:233-243.

Kreitzer AC, Regehr WG (2001) Cerebellar depolarization-induced suppression of inhibition is mediated by endogenous cannabinoids. J Neurosci 21:RC174(1-5).

Llano I, Leresche N, Marty A (1991) Calcium entry increases the sensitivity of cerebellar Purkinje cells to applied GABA and decreases inhibitory synaptic currents. Neuron 6:565-574.

Llano I, Gonzales J, Caputo C, Lai FA, Blayney LM, Tan YP, Marty A (2000) Presynaptic calcium stores underlie large-amplitude miniature IPSCs and spontaneous calcium transients. Nat Neurosci 3:1256-1265.

Malinow R, Tsien RW (1990) Presynaptic enhancement shown by wholecell recordings of long-term potentiation in hippocampal slices. Nature 346:177-180.

Mothet JP, Fossier P, Meunier FM, Stinnakre J, Tauc L, Baux G (1998) Cyclic ADP-ribose and calcium-induced calcium release regulate neurotransmitter release at a cholinergic synapse of Aplysia. J Physiol (Lond) 507:405-414.

Narita K, Akita T, Osanai M, Shirakasi T, Kijima H, Kuba K (1998) $\mathrm{A} \mathrm{Ca}^{2+}$. induced $\mathrm{Ca}^{2+}$ release mechanism involved in asynchronous exocytosis at frog motor nerve terminals. J Gen Physiol 112:593-609.

Peng Y (1996) Ryanodine-sensitive component of calcium transients evoked by nerve firing at presynaptic nerve terminals. J Neurosci 16:6703-6712.

Savic N, Sciancalepore M (1998) Intracellular calcium stores modulate GABA-mediated synaptic currents in neonatal rat hippocampal neurons. Eur J Neurosci 10:3379-3386.

Simkus CRL, Stricker C (2002) The contribution of intracellular calcium stores to mEPSCs recorded in layer II neurons of rat barrel cortex. J Physiol (Lond) 545:521-535.

Smith AB, Cunnane TC (1996) Ryanodine-sensitive calcium stores involved in neurotransmitter release from sympathetic nerve terminals of the guinea-pig. J Physiol (Lond) 497:657-664.

Tan YP, Llano I (1999) Modulation by $\mathrm{K}^{+}$channels of action potentialevoked intracellular $\mathrm{Ca}^{2+}$ concentration rises in rat cerebellar basket cell axons. J Physiol (Lond) 520:65-78.

Valdivia HH, Kaplan JL, Ellis-Davies GCR, Lederer WJ (1995) Rapid adaptation of cardiac ryanodine receptors: modulation by $\mathrm{Mg}^{2+}$ and phosphorylation. Science 267:1997-2000.

Vincent P, Marty A (1996) Fluctuations of inhibitory postsynaptic currents in Purkinje cells from rat cerebellar slices. J Physiol (Lond) 494:183-199.

Vincent P, Armstrong CM, Marty A (1992) Inhibitory synaptic currents in rat cerebellar Purkinje cells: modulation by postsynaptic depolarization. J Physiol (Lond) 456:453-471. 